ESTUDIOS

\title{
Os efeitos jurídicos do salário-maternidade na barriga de aluguel
}

\author{
The Legal Effects of Maternity Wage on the Surrogacy \\ Gilberto Ferreira Marchetti Filho \\ Centro Universitário da Grande Dourados, Brasil \\ Juliana de Oliveira Xavier Ribeiro \\ Instituto Nacional de Formação Continuada, Brasil
}

\begin{abstract}
RESUMO O direito de família é uma das áreas do direito que mais evoluíram nos últimos anos diante da sociedade moderna. Seguindo essa evolução, o conceito de filiação e os métodos de concepção e de geração se desenvolveram pela ciência. A modernização da fertilização in vitro e o desejo de ser mãe ou pai tornou a maternidade de substituição, conhecida como barriga de aluguel, uma prática social que traz consequências importantes para o direito, como a legalidade desse negócio, suas repercussões no direito de família e das sucessões, e no direito previdenciário, ponto que se pretende enfocar aqui. Portanto, essa pesquisa tem por objetivo analisar as consequências jurídicas da barriga de aluguel na concessão de benefícios previdenciários como o salário-maternidade.
\end{abstract}

PALAVRAS-CHAVE Direito de família, direito previdenciário, maternidade de substituição, barriga de aluguel, salário-maternidade.

ABSTRACT Family law is one of the areas of law that has evolved the most in recent years in the face of modern society. Following this evolution, the concept of affiliation and the methods of conception and generation were developed by science. Modernization of IVF and the person's desire to be a mother or father made maternity replacement, known as surrogacy, a social practice that has important consequences for the law, such as the legality of this business, its repercussions on family and succession law, and on social security law, point that it intends to focus on here. Therefore, this research aims to analyze the legal consequences of surrogacy in granting social security benefits such as maternity wages. 
KEYWORDS Family law, social security law, replacement maternity, surrogacy, maternity wage.

\section{Introdução}

O epistemólogo jurídico busca ideologias para adequar nosso arcabouço jurídico aos novos acontecimentos. Neste diapasão, preencher as lacunas legais é o maior desafio concedido ao jurista na pós-modernidade.

Não há no ordenamento jurídico brasileiro um preceito que vise guiar nosso operador do Direito quanto à concessão do salário e da licença-maternidade nos casos da maternidade de substituição. Este tema, também diante da gritante insuficiência de mecanismos regulamentadores, se socorre de princípios constitucionais e de normas do Conselho Federal de Medicina a fim de detectar caminhos que visem solucionar as ocorrências hodiernas no plano concreto.

Busca-se com este estudo tentar dirimir possíveis dúvidas e traçar caminhos jurídicos que poderão ser utilizados como paradigmas em questões futuras. Impende salientar que a ausência de leis específica sobre o mérito levará ao livre arbítrio do magistrado pátrio a decidir, conforme o seu convencimento, quem fará jus a licença e o salário-maternidade nas hipóteses útero de substituição. Atualmente há um cenário que culmina a uma vasta insegurança jurídica, pois não há qualquer uniformidade nas decisões de nossos Tribunais quanto ao tema proposto.

O Direito de família está sofrendo adequações quanto à subsunção das normas aos casos da atualidade. Novos modelos de famílias surgem e com isso novas demandas jurídicas de adequação as estas entidades familiares são aprimoradas.

Adicionalmente até mesmo o salário e a licença-maternidade têm sido objeto de alterações em seu conteúdo jurídico dentro da seara da previdência social brasileira. Entretanto, o Direito previdenciário Brasileiro não tem seguido estas rápidas evoluções de cunho biotecnológico ligados à reprodução humana assistida, principalmente quanto à barriga de aluguel.

Diante desta celeuma, não há um conceito legal ou uma hipótese de incidência descrita em lei que trace os procedimentos da concessão desta prestação previdenciária para todas as mulheres envolvidas no processo de maternidade de substituição.

Notório relatar que a mãe de substituição que é segurada do sistema previdenciário e sofre os efeitos do parto é sujeito ativo desta prestação. Porém, como ficará a questão da mãe biológica que não gerou a criança nas hipóteses permitidas de maternidade de substituição no Brasil, refletindo além dos casos legais, como ficaria a concessão do salário-maternidade em face do INSS caso fosse legalizado os casos contratuais da barriga de aluguel no Brasil. 
Cumpre analisarmos a ampla lacuna de acordo com o processo de integração da norma jurídica, com o propósito de conceder singela colaboração para questões que possam ocorrer em um futuro breve.

\section{A família moderna, as novas formas de filiação e a maternidade de substituição no Brasil}

O debate acerca de temas relacionados à bioética e biodireito está cada vez mais em evidência no cenário do direito. Deveras, falar sobre essas questões é desafiador na cena jurídica. Mas não se pode afastar sua importância para evolução do conhecimento, da pesquisa e do próprio ordenamento jurídico que precisa acompanhar a evolução de temas cada vez mais complexos.

Desses temas polêmicos que envolvem a bioética e o biodireito, temos, sem sobra de dúvidas, a questão relativa à maternidade de substituição, seja pela barriga solidária ou pela barriga de aluguel.

Com efeito, o biodireito tem «a vida por objeto principal, salientando que a verdade científica não poderá sobrepor-se à ética e ao direito, assim como o progresso científico não poderá acobertar crimes contra a dignidade humana, nem traçar, sem limites jurídicos, os destinos da humanidade» (Diniz, 2006: 9).

Da mesma forma, quando se fala em bioética - fonte imediata do biodireito -, sua base paradigmática reside exatamente na pessoa humana e seu valor supremo, «de sua vida, dignidade e liberdade ou autonomia, dentro da linguagem dos direitos humanos e em busca de uma qualidade de vida digna, dando, portanto, prioridade ao ser humano e não às instituições voltadas à biotecnociência» (Diniz, 2006: 14).

Significa dizer que, falar em maternidade de substituição ou barriga de aluguel envolve diretamente conceitos e ideais que são objetos de estudos da bioética e do biodireito.

Mas antes de adentrar nesse assunto específico, é preciso compreender que a família moderna tem sofrido grandes evoluções, o que também tem levado a profundas discussões e sopesamentos acerca de temas que ganham grande evidência na cena jurídica atual.

O conceito de família é um dos temas no direito civil que mais sofreu evolução nos últimos anos, recebendo novos significados, conforme a evolução e desenvolvimento da sociedade mundial e, no específico, brasileira.

Para Maria Helena Diniz, os legisladores elaboram diariamente novas normas para acompanhar a evolução da sociedade, assim como os tribunais introduzem novos preceitos constantemente, fazendo com que valores sofram mutações com o decorrer do tempo. Assim, para atender às mudanças e evoluções da sociedade, novas regras são criadas, sendo uma constante o dinamismo social (Diniz, 2009: 173).

Diante disso, o conceito de família foi alargado recebendo uma definição muito 
mais ampla. É certo que, atualmente, família pode dizer respeito a um ou mais indivíduos, ligados biologicamente ou por traços socioafetivos, com a finalidade de desenvolver a personalidade de cada um.

A família é, portanto, a instituição social primária, sendo um regime de relações interpessoais e sociais com a finalidade de colaborar para a realização das pessoas humanas que compõem um determinado núcleo.

A Constituição Federal de 1988, em seu art. 226, posiciona a família como o alicerce da sociedade civil com especial proteção dada pelo Estado.

Mas aquela ideia de família única, constituída apenas pelo casamento, não tem mais na sociedade moderna. Não reconhecer outras espécies de agrupamentos como instituições familiares não atende mais a necessidade do próprio direito, muito menos tem amparo no texto constitucional (Oliveira, 2002: 216).

Assim, não é somente a «família tradicional», fundada no casamento, a que cumpre a função social a ela atribuída, mas também os vários outros arranjos familiares, criados pela sociedade contemporânea. Esses têm cumprido essa finalidade, que é a transmissão da cultura e formação da pessoa humana digna.

Maria Berenice Dias afirma que família em seu sentido mais puro e jurídico do termo é qualquer relacionamento de amor, afeto, carinho, solidariedade, compaixão e compreensão presentes entre aqueles que estão envolvidos no grupo, desde que assim se reconheçam (Dias, 2009: 124).

Assim, família é um conjunto de pessoas que se reconheçam como tal, ligadas pelo afeto, não importando o gênero sexual dos integrantes, o que amplia grandemente as formas de instituição familiar.

Ao lado da ideia moderna de família, há também a necessidade de se compreender o novo conceito de filiação, que, verdadeiramente, não se resume ao elo que liga biologicamente o pai ou mãe à sua prole e que gera um vínculo jurídico entre as pessoas integrantes de uma família (Madaleno, 2011: 471).

Deveras, é o fator biológico que gera uma situação para o direito, a maternidade e paternidade jurídica (Fujita, 2009: 62). No entanto, por diversos motivos, essa noção de vinculação biológica pode não gerar a vinculação jurídica. Seja porque não há o afeto com o filho, ou porque a filiação foi gerada por doação de sêmen ou óvulos de terceiros, em razão de infertilidade ou impossibilidade de procriação biológica do pai ou da mãe.

Nisso temos os meios de concepção científicos e as biotécnicas de reprodução, com métodos cada vez mais evoluídos de fertilização in vitro, bancos de sêmen e óvulos, catálogos genéticos e muito mais. Tudo acaba por provocar discussões importantes no campo do direito de família e do biodireito. E que, direta ou indiretamente, acaba por atingir o direito previdenciário.

Uma dessas discussões é exatamente a maternidade de substituição, seja pela barriga solidária ou barriga de aluguel. 
Historicamente, a ideia da maternidade sempre partiu do pressuposto baseado na máxima latina mater semper certa est, ou seja, a maternidade é sempre certa. Isso porque se tinha a ideia de que quem dava à luz era efetivamente a mãe da criança.

Contudo, as técnicas modernas de reprodução, os bancos de gametas masculino e, principalmente feminino, além da possibilidade de doação de óvulos, abriu uma grande brecha nessa máxima que até pouco tempo atrás parecia intocável.

O campo de discussão desse tema é imenso. Maria Helena Diniz traz alguns questionamentos que esse tema pode gerar

Se o óvulo não for o da esposa, mas de uma doadora, quem será a mãe? A doadora? Ou a esposa em cujo útero foi implantado o óvulo de outra, fecundado pelo sêmen do marido? Dever-se-á presumir, a priori, que partus sequitur ventrem, ou seja, a maternidade se determina pelo parto da mulher que deu à luz? A quem o judiciário deverá entregar a criança? (Diniz, 2006: 574)

Veja que «fácil é perceber que o princípio mater semper certa est ficou abalado com o avanço da biotecnologia e da engenharia genética» (Diniz, 2006: 575). E não é só. Temos exatamente nessa discussão a questão relativa à maternidade de substituição, popularmente conhecida como barriga de aluguel.

Aqui, mais questões podem surgir, como e se a pessoa que cedeu o «ventre pretender reconhecer como seu o filho, reclamando-o judicialmente. Como solucionar tal pretensão?» E se houve um planejamento, com fertilização in vitro? A criança seria filho de quem cedeu o ventre, ou de quem doou o óvulo, ou de quem planejou a concepção pela fertilização?

E principalmente, para o quanto nos interessa aqui esse estudo, como ficaria a questão previdenciária nessa problemática, notadamente no tocante ao salário-maternidade e a licença maternidade? Quem sustentou a gestação teria direito? Ou a mãe biológica? Ou ainda, quem doou o óvulo, ou quem planejou, pela fertilização in vitro, principalmente quando se tratar de mulher com estéril, homem solteiro ou casais homoafetivos?

Observa-se que se trata de tema polêmico e que demanda reflexões profundas, eis que já é uma realidade na sociedade brasileira e que não há qualquer regulamentação jurídica sobre. De fato, a despeito do Código Civil ser de 2002, ou seja, do início do Século XXI, «não se verifica em seu bojo tratamento da intitulada cessão temporária de útero, não obstante o fato de que o vulgarmente chamado "útero de aluguel" seja uma realidade na vida de muitos indivíduos com dificuldades de reprodução» (Silva, 2008: 80).

Nessa linha, para iniciar a compreensão e buscar solução no campo previdenciário, temos que entender o que é a maternidade de substituição e seus aspectos principais.

Pois bem. Sabemos que por motivos diversos, muitas vezes uma pessoa não pode 
gerar um filho. Seja por questões físicas, ou pela infertilidade, ou por problemas de saúde que impossibilitam a mulher de carregar o feto no seu ventre, é fato que isso sempre existiu na sociedade.

É exatamente nessa situação, quando não há a possibilidade de gerar e cumprir a gestação que entra o interesse na maternidade de substituição ou cessão de útero. «É uma alternativa de esperança para os casais, ou para um indivíduo, de realizar o sonho da maternidade e paternidade. Nesse ínterim, após tentarem de tudo, recorrem a Maternidade por Substituição, também denominada por Cessão Temporária do Útero» (Freire Júnior e Andrade Batista, 2017).

Quando afirmamos que a maternidade de substituição sempre existiu na sociedade, queremos dizer que o tema em si não é nada novo. Há registros de situações parecidas - mas em forma bem arcaica - no Império Romano e na Idade Média. Passagens da Bíblia também dão conta da prática em Gênesis, capítulo 16 e 30, nas histórias de Abrão e Jacó. Tudo para se viver a maternidade.

No imaginário humano, podemos também lembrar de filmes como «Uma mãe para o meu bebê», de 2008, e «The Surrogacy Trap», de 2013; além da novela «Barriga de Aluguel», transmitida entre os anos de 1990 e 1991.

Mas o que é barriga de aluguel, na linguagem jurídica? Tecnicamente, a expressão «barriga de aluguel» faz parte do gênero maternidade de substituição, ou cessão temporária de útero. Maria Helena Diniz usa o termo «locação de útero» ou «ventre mercenário» (Diniz, 2006: 587).

Trata-se de meio pelo qual uma mulher cede seu útero para a gestação de um embrião concebido in vitro por meio de técnica de reprodução assistida e, cumprido o período gestacional, se obriga a entregar a criança após o parto, para outra pessoa, que pode ou não ter fornecido parte do material genético utilizado na fertilização.

Em verdade, a maternidade de substituição «não consiste propriamente numa técnica reprodutiva, embora estudada como tal» (Silva, 2016: 19). É, como dito, mais uma «opção para casais que não conseguem ter filhos por algum problema de saúde e não por preocupações estéticas ou pelas dores do parto, por exemplo» (Teixeira, 2016: 131).

Na doutrina encontramos duas formas de classificação da maternidade de substituição: quanto à formação do embrião e quanto à onerosidade. Quanto a fertilização do embrião, a maternidade de substituição será homóloga quando o embrião resultar de fertilização resultar de gametas dos titulares do projeto parental; e será heteróloga, quando o material genético não pertencer a um deles ou em relação à ambos (Gama, 2003: 745-747).

Mas, sem dúvida nenhuma, a classificação que mais interessa para a pesquisa está relacionada a onerosidade. Diz-se que a maternidade de substituição é gratuita quando não há contraprestação pela cessão do útero. Trata-se da barriga solidária, modalidade de maternidade de substituição estritamente altruísta.

Por sua vez, a maternidade de substituição é onerosa quando a mulher que cede 
o útero recebe contraprestação por ela, como uma espécie de aluguel ou pagamento pela utilização do útero alheio.

A grande questão e polêmica que envolve a maternidade de substituição, notadamente na modalidade onerosa, está na sua possibilidade jurídica, ou até mesmo licitude no direito brasileiro. Isso porque, em regra, no campo dos direitos da personalidade, salvante algumas exceções reconhecidas pela própria lei, a legislação brasileira veda qualquer ato de disposição do próprio corpo.

Nesse sentido, o art. 199, $\$ 4^{\circ}$, da Constituição Federal é claro no sentido de que vedar «todo tipo de comercialização» de «órgãos, tecidos e substâncias humanas para fins de transplante, pesquisa e tratamento, bem como a coleta, processamento e transfusão de sangue e seus derivados».

No mesmo sentido, o Código Civil estabelece, nos arts. 11, 13 e 14, que «com exceção dos casos previstos em lei, os direitos da personalidade são intransmissíveis e irrenunciáveis, não podendo o seu exercício sofrer limitação voluntária». E, «salvo por exigência médica, é defeso o ato de disposição do próprio corpo, quando importar diminuição permanente da integridade física, ou contrariar os bons costumes». Assim, somente «é válida, com objetivo científico, ou altruístico, a disposição gratuita do próprio corpo, no todo ou em parte, para depois da morte».

Ora, dentro de uma interpretação sistemática da Constituição e do Código Civil, considerando que a cessão do útero, seja gratuita ou onerosa, envolve disposição do próprio corpo, tem-se que o negócio jurídico base e que resulta na «barriga solidária» ou na «barriga de aluguel» é nulo, dada a ilicitude do seu objeto, nos termos do art. 166, inciso II, do Código Civil.

Para amenizar a situação, o Conselho Federal de Medicina publicou, em 2013, a Resolução 2013 na qual «adota as normas éticas para a utilização das técnicas de reprodução assistida, anexas à presente resolução, como dispositivo deontológico a ser seguido pelos médicos». ${ }^{.}$Nela, o órgão regulador da medicina no Brasil, no capítulo VII, autorizou a «gestação de substituição, desde que exista um problema médico que impeça ou contraindique a gestação na doadora genética ou em caso de união homoafetiva».

Para tanto, nos itens 1 e 2 desse capítulo, estabeleceu que «as doadoras temporárias do útero devem pertencer à família de um dos parceiros num parentesco consanguíneo até o quarto grau [...], em todos os casos respeitada a idade limite de até 50 anos», ${ }^{2}$ vendando qualquer forma lucrativa ou comercial da cessão.

1. Conselho Federal de Medicina, adota as normas éticas para a utilização das técnicas de reprodução assistida, anexas à presente resolução, como dispositivo deontológico a ser seguido pelos médicos e revoga a Resolução CFM 1.957/10. «Resolução CFM n. 2013/2013». Diário Oficial [da] República Federativa do Brasil, Brasília, mayo.

2. Conselho Federal de Medicina, adota as normas éticas para a utilização das técnicas de reprodução assistida, anexas à presente resolução, como dispositivo deontológico a ser seguido pelos médicos, 2013 
Observa-se, pois, que se trata de assunto de infindáveis discussões, nos mais diversos campos, começando pelos direitos fundamentais, passeando pelo direito civil e penal, inclusive.

Seja como for, sua prática na sociedade brasileira é uma realidade, tanto na modalidade gratuita quanto onerosa. E o direito não pode ignorar a situação, solucionando-a com o simples argumento de que o negócio que originou a gestação em útero de substituição é nulo. Mesmo porque existe uma criança que está sendo gerada e as consequências disso são irreversíveis, ainda que se declare a nulidade do negócio.

Diante disso, passamos ao enfoque do estudo na questão, que é as implicações da maternidade de substituição no direito previdenciário.

\section{O salário-maternidade no Âmbito do Regime Geral de Previdência Social}

Breve incursão histórica dos dispositivos internacionais sobre a proteção à maternidade

A contingência «maternidade» no direito pátrio advém dos critérios da Convenção 102 da Organização Internacional do Trabalho, que dispõe sobre o mínimo previdenciário, e que entrou em vigor no plano internacional em 27 de abril de 1955. A Convenção 102 da OIT é um dos mais importantes instrumentos internacionais, pois retrata as «normas mínimas para a seguridade social» frente a nove contingências clássicas: idade avançada, maternidade, acidente de trabalho, responsabilidades familiares, desemprego, tratamento médico, morte, invalidez e enfermidade (OIT, 1952).

Em seu art. 47, a Convenção assegura que seus Estados-membros devem conceder prestações ou subsídios de maternidade àqueles que estão dentro do rol de sua hipótese de incidência. Adicionalmente, o seu art. 47 elucida que a contingência «maternidade» englobará a gravidez, o parto e suas consequências, bem como a suspensão de ganhos.

As prestações da maternidade na Convenção 102, nas palavras de Andréa Regina Galvão Presotto, visam cobrir a suspensão de ganhos decorrente da gravidez, do parto e suas consequências (Presotto, 2011: 61).

Ao analisarmos intrinsecamente os ditames da citada Convenção, verificaremos que ao descrever que suas hipóteses de incidência entre gravidez, parto e suas consequências, haverá uma abertura no leque que objetivará trazer novas questões oriundas do novo direito das famílias e as novas modalidades de filiação.

O conceito de família vem sendo alterado na evolução da História, tendo em vista que inúmeras modificações de caráter público e privado tem sido o âmago deste redimensionamento da sociedade.

A família sai do seu contexto tradicional formada pelo casamento, para introduzir novos valores da pós-modernidade, no qual o respeito ao ser humano quanto à busca 
de sua dignidade e dos direitos inerentes à sua personalidade, ressalta a importância do reconhecimento de novas formas de família.

Sergio Resende de Barros sintetiza que «os direitos humanos tendem à concretude, que completa a universalidade à que pretendem. Admitir alguma exclusão seria negar o direito de família no seu núcleo fundamental, o direito de família, inibindo à teoria e a prática dos direitos humanos filiais» (Barros, 2003: 85).

Como reflexo do risco social «família», a proteção à maternidade têm sido objeto de vários instrumentos internacionais cujo intuito é também a proteção do labor feminino. A Declaração Americana dos Direitos e Deveres do Homem de 1948, ocorrida em Bogotá, no dia o2 de maio de 1948 reconheceu em seu capítulo VII que «toda mulher em estado de gravidez na época de lactância assim como seu filho tem direito a proteção, cuidados e ajudas especiais»; enquanto a Declaração dos Direitos do Homem, realizada em Paris no dia 10 de dezembro do mesmo ano reconheceu em seu art. XXV, item 2, que a maternidade e a infância «têm direitos a cuidados especiais».

Interessante mencionar que a dita Convenção garante para todas as crianças, nascidas dentro ou fora do matrimônio a universalidade no que diz respeito à proteção social. Não obstante desde os meados de 1950 já se reconhece as novas formas de família que seriam abarcadas pelas futuras legislações cíveis

Elimar Szaniawski ilustra que a concepção transmoderna de família não mais enquadra somente um único modelo de família que antes era representada pelo matrimônio. Novos tipos de família, como a união estável, o concubinato e a família monoparental encontraram seu espaço no arcabouço normativo (Szaniawski, 2019: 27).

No momento que as novas formatações de família se encontram reconhecidas no mundo jurídico, os filhos advindos desta relação de parentalidade também gozaram dos efeitos jurídicos oriundos da referida proteção à maternidade.

A proteção à parentalidade foi um dos pioneiros objetos de regulamentação pela Organização Internacional do Trabalho (OIT). A natureza protetiva do trabalho da mulher antes e após o parto foi o assunto retratado na Convenção o3 da OIT, de 19 de junho de 1921. Ampliando seu campo de atuação, a Convenção o3 foi revista em 1952. Dia 07 de setembro de 1955 a Convenção 103 entrou em vigor com a finalidade de amparar mais setores do trabalho da mulher bem como determinou no seu art. $4^{\circ}$, item 1,0 direito assegurado à mulher de receber prestações em espécie do período que estivesse afastada para cuidar dos efeitos ocasionados com o parto.

Dentre os direitos previstos, no mencionado dispositivo internacional, foi concedida a natureza de proteção social oriunda do seguro social a fim de que os pagamentos dos períodos de afastamento fossem realizados por fundos públicos. O objeto central desta proteção teve o cunho de relativização da mão-de-obra feminina e a não discriminação da mulher no mercado de trabalho.

Posteriormente, a Recomendação 95 de 1952 elucidou que o prazo da licença-pa- 
rental deveria ser aumentado para 14 semanas, na hipótese que as saúdes da mãe ou do pai exigisse tal afastamento.

As normas de cunho nitidamente tutelar passam a ser revistas, com o propósito de conceder uma maior flexibilização e adequação as necessidades fáticas da época. Por esta razão, normas de natureza antidiscriminatória do trabalho da mulher foram o foco central da nova série de normativas internacionais. ${ }^{3}$

Neste raciocínio Marly Cardone ilustra que as leis podem ter efeitos educativos e transformadores de forma a induzir certo comportamento que seria considerado mais justo para o indivíduo e a sociedade (Cardone, 1977/1978: 3). Há casos em que a lei vem atender o reclamo da sociedade, e se antecipa a essa reivindicação social, buscando arquitetar uma conduta por esta idealizada.

O Protocolo 1990, no seu art. 3, é um típico exemplo deste mérito, tendo em vista que proíbe o trabalho noturno da gestante. Porém, lhe dá a opção de exercê-lo caso não prejudique sua saúde ou do bebê que está esperando.

Nessa evolução histórica, a Convenção 183 da OIT, de 15 de julho de 2000, revisou as convenções anteriores. Miguel Horvath Júnior afirmou que seu preâmbulo objetivou a necessidade de se conceder proteção à gravidez com responsabilidade dividida entre Estado e sociedade, objetivando a promoção da igualdade entre homens e mulheres, por intermédio da inovação da licença-parental (Horvath Júnior, 2004: 61).

\section{O histórico do salário-maternidade no ordenamento jurídico brasileiro}

A proteção à maternidade no Brasil foi primeiramente objeto de regulação em nível constitucional com a Constituição Getulista de $1934 .{ }^{4}$ Dentro de uma nova era para as trabalhadoras brasileiras, o Decreto 21.417 de 17 de maio de 1932 trouxe várias formas de proibição labor para a gestante e lhe garantiu o descanso de quatro semanas depois do parto.

Na evolução dos textos constitucionais pátrios, a Constituição de 1937 concretizou a proteção à maternidade nos moldes do art. 137, l, retirando a estabilidade no emprego, que passou a ter amparo legal posteriormente na Constituição de 1946, no seu art. 157, inciso X. Já a Carta de 1967, arts. 158, incisos XI e XVI evidenciou a presença da maternidade como um risco social. Contudo, somente em 1988, com a publicação da Constituição cidadã, o sistema de seguridade social pátrio passou a elencar necessidades sociais como eventos sujeitos à proteção ampla e irrestrita.

3. O teor da Convenção sobre a eliminação de todas as formas de Discriminação contra a mulher de 1979 é a base de todas as outras normas de proteção ao trabalho feminino bem como da proteção à maternidade.

4. O art. 121, parágrafo $1^{\circ}$, h, e $\$ 3^{\circ}$ e o art. 138, c da Constituição Federal Brasileira de 1934 estabeleceram primeiras normas constitucionais de proteção à gestante. 
Nas doutrinas de Almansa Pastor conseguiremos identificar especificamente a maternidade como um risco ou uma contingência. $O$ doutrinador diferencia os riscos de contingências relatando que essas constituem as causas primárias das necessidades que guarnecem de proteção enquanto os riscos são as secundárias, sendo o fato gerador da contingência (Pastor, 1991: 229).

Nesse diapasão, refletiremos que o autor entende que a maternidade é a contingência que deriva dos riscos gerados pelas ocorrências da incapacidade laboral oriundas do parto como também do prejuízo econômico relativo à impossibilidade laboral.

Augusto Venturi esclarece que a maternidade, em isonomia a enfermidade, comporta a cessação do trabalho e a consequente perda de valores salariais (Venturi, 1995: 162).

Ao tratarmos da evolução do conceito de risco do seguro social para a seguridade social, verificaremos que o novo modelo de proteção social se traduziria na necessidade social, o que ampliaria o rol de hipóteses de incidência para o salário-maternidade.

Dentro deste contexto, Almansa Pastor ressaltou:

La progresión última camina hacia la unificación de la protección, independiente de la causa secundaria productora, teniendo em cuenta tan sólo la situación de necesidad y contingencia que origina. En el momento que la unificación se produzca, el riesgo como causa secundaria [...] perderá su razón de ser y es que, racionalmente, la misma necesidad, que es lo que si persigue cubrir y satisfacer (Pastor, 1991: 233).

As reflexões advindas da eclosão da necessidade social para as hipóteses da maternidade trazem à tona novas formas de proteção que deverão ser analisadas por ocasião das hodiernas espécies de maternidade, entre elas a maternidade de substituição ou barriga de aluguel.

Regras atuais sobre o salário e a licença-maternidade no Regime Geral de Previdência Social

A Lei 8.213 de 24 de julho de 1991 traz em seus artigos 71 a 73 as regras vigentes sobre o salário-maternidade no regime geral de previdência social brasileira.

Para que possamos compreender esta hipótese de incidência, deveremos analisar que não somente na maternidade natural, haverá origem a prestação, mas também nas questões de maternidade adotiva, guarda e na maternidade socioafetiva.

Quando nos referirmos à maternidade biológica haverá no critério material da hipótese de incidência a ocorrência do parto que pode ser compreendido o nascimento ocorrido a partir da $23^{a}$ semana de gestação.

De fato, este estará consumado se houver o nascimento com o sem vida a partir deste prazo legal pela ocorrência da viabilidade fetal, isto é a possibilidade da sobrevivência da criança a partir do $6^{\circ}$ mês de gestação da mãe. O artigo 71 da Lei 8.213 
de 1991 determina o pagamento do benefício «durante 120 (cento e vinte) dias, com início no período entre 28 (vinte e oito) dias antes do parto e a data de ocorrência deste, observadas as situações e condições previstas na legislação no que concerne à proteção à maternidade».5

Para efeitos do seguro social pátrio, a mãe que perde seu filho antes do período da viabilidade fetal terá sofrido abordo. Para tanto e de acordo com o art. 92, $\$ 5^{\circ}$, do Decreto 3048/99, serão concedidos licença e salário-maternidade, cujo período será de duas semanas.

Como forma equiparada, temos primeiramente a Lei 10.421/o2, que deu origem a contingência da maternidade adotiva no Brasil estabelecendo os parâmetros de sua concessão. E posteriormente, o art. 71-A da Lei de Benefícios veio estabelecer novas regras concessórias para a adotante ou a guardião que tenha intenção de adotar.

Ao segurado ou segurada da Previdência Social que adotar ou obtiver guarda judicial para fins de adoção de criança é devido salário-maternidade pelo período de 120 (cento e vinte) dias e o seu pagamento será diretamente pela Previdência Social.

Por sua vez, o $₫ 2^{\circ}$ do art. 71-A traz um polêmico item que, no caso de adoção, não poderá ser concedido o benefício a mais de um segurado, decorrente do mesmo processo de adoção, ainda que os cônjuges ou companheiros estejam submetidos a Regime Próprio de Previdência Social. Sendo assim, um casal homoafetivo feminino deverá escolher quem fará jus a licença de 120 dias.

A questão que poderá ser debatida posteriormente é se em caso de duas mães socioafetivas somente uma poderá gozar do benefício. Este dispositivo fere o princípio da proteção integral da criança, pois a natureza jurídica do salário-maternidade não é somente proteger as mulheres que dão à luz dos efeitos do parto, mas sim tornar viável a integração dos pais desta criança no ambiente familiar.

Em 2019 foi estabelecida a repercussão no Supremo Tribunal Federal sobre a concessão de licença-maternidade à mãe não-gestante, que constitui união estável homoafetiva, após inseminação artificial heteróloga de sua companheira. Nesta hipótese, em breve a decisão do Recurso Extraordinário 1.211.446 pelo Pleno do Supremo nos guiará a uma resposta.

Nas manifestações da repercussão geral o Ministro Fux destacou:

Por todo o exposto, depreende-se que a questão constitucional ora debatida apresenta repercussão geral sob o prisma social, jurídico e econômico: i) social, em razão da própria natureza do direito à licença-maternidade e do impacto gerado pela sua extensão a qualquer servidora pública ou trabalhadora (art. $7^{\circ}$, XVIII, e art. $39, \S 3^{\circ}$, da Constituição Federal) que vivencie a situação fática sub examine; ii) jurídico, posto que envolve a proteção especial consagrada à maternidade (CF, art. $6^{\circ} \mathrm{c} / \mathrm{c}$ art. 201),

5. Brasil, dispõe sobre os Planos de Benefícios da Previdência Social e dá outras providências. «Lei Federal n. 8.213/1991». Diário Oficial [da] República Federativa do Brasil, Brasília, julio. 
bem como a construção do âmbito de incidência do art. $7^{\circ}$, XVIII, da Constituição Federal, que deve albergar as múltiplas hipóteses de criação do vínculo maternal; e iii) econômico, porque discute a concessão de benefício de natureza previdenciária, com custos para a coletividade e reflexos no equilíbrio atuarial dos sistemas de previdência social. ${ }^{6}$

Enfim, a Lei 13.301/16, que dispõe sobre a adoção de medidas de vigilância em saúde quando verificada situação de iminente perigo à saúde pública pela presença do mosquito transmissor do vírus da dengue, do vírus Chikungunya e do vírus da Zika, em seu art. $18, \$ 3^{\circ}$ estabelece a extensão da licença maternidade para 180 dias para as mães de crianças acometidas por sequelas neurológicas de doenças transmitidas pelo Aedes Aegypti como a microcefalia.

Não haverá carência para as seguradas, empregadas, empregadas domésticas e avulsas. Na hipótese de seguradas facultativas a carência será de 10 meses de contribuição, enquanto para a segurada especial será de 10 meses de prova de atividade rural.

Por ocasião de parto antecipado, o período de carência de 10 meses será diminuído em número de contribuições equivalente ao número de meses em que o parto foi antecipado.

A jurisprudência de nossos tribunais também tem decidido que, em casos de gravidez de alto risco, haverá isenção de carência para as contribuintes individuais. Nesse sentido:

Previdenciário. Benefício por incapacidade. Hipóteses de dispensa de carência. Gravidez de alto risco. 1. Em casos de gravidez de alto risco, com necessidade de repouso da gestante, o artigo 26, inciso II, da Lei 8.213/1991 deve ser interpretado ampliativamente, à luz do direito constitucional à proteção da gestante, bem como à vida, à maternidade e à infância, nos termos dos artigos $5^{\circ}$, caput, $6^{\circ}$, caput, 201, inciso II e 203, inciso I, da Carta Magna, de modo a se concluir pela dispensa de carência. Neste sentido: TRF4, Apelreex 0016508-23.2015.404.9999, Quinta Turma, Relator Paulo Afonso Brum Vaz, D.E. 21/o1/2016; TRF4, AC 0009725-15.2015.404.9999, Quinta Turma, Relator Rogerio Favreto, D.E. 09/09/2015; 5006699-24.2012.404.7122, Turma Regional de Uniformização da $4^{a}$ Região, Relator José Antonio Savaris.?

$\mathrm{O}$ art. $71-\mathrm{B}, \S 3^{\circ}$, da Lei Previdenciária de Benefícios enumera as questões do critério quantitativo referente ao valor estipulado para o salário-maternidade. Sendo

6. Supremo Tribunal Federal. Recurso Extraordinário n. 1211446. Relator Ministro Luiz Fux (2019). Diário da Justiça [da] República Federativa do Brasil, Brasília (novienbre).

7. Tribunal Regional Federal da $4^{a}$ Região. Apelação Cível n. 5002072-75.2019.4.04.7107. Relator Desembargador Federal Selmar Saraiva da Silva Filho (2019). Diário Eletrônico da Justiça Federal da $4^{a}$ Região, Porto Alegre (agosto). 
assim, será a remuneração integral, para o empregado e trabalhador avulso (art. 72 da Lei 8.213/91); o último salário-de-contribuição, para o empregado doméstico; 1/12 (um doze avos) da soma dos 12 (doze) últimos salários de contribuição, apurados em um período não superior a 15 (quinze) meses, para o contribuinte individual, facultativo e desempregado e o valor do salário mínimo, para o segurado especial.

No caso da gestante empregada, caberá à empresa pagar o salário-maternidade devido à respectiva empregada gestante, efetivando-se a compensação, quando do recolhimento das contribuições incidentes sobre a folha de salários e demais rendimentos pagos ou creditados, a qualquer título, à pessoa física que lhe preste serviço.

\section{A concessão do salário-maternidade e da licença-maternidade nos casos de barriga de aluguel}

Com fundamento em nosso atual ordenamento jurídico e pelo princípio da maternidade sempre é certa, somente poderia pleitear a prestação do salário-maternidade aquela que deu à luz a criança, salvo nas hipóteses de adoção previstas na Lei 8.213 de 24 de julho de 1991. Contudo, como vimos, a maternidade deixou de ser definida de modo simples e categórico de acordo com o velho aximoma mater semper certa est (Barbas, 2006: 145).

Cumpre repetirmos, para tal mérito, que a mãe biológica, como pretendente à maternidade, é aquela que forneceu material genético para a fertilização «in vitro».

Verificamos nesta hipótese, uma simples aplicação da analogia utilizando para a referida mãe que possui um vínculo de filiação consanguínea com seu filho, os ditames do salário-maternidade e a sua regra-matriz de incidência para a mãe adotiva.

Apesar desta mãe não ter passado pelo processo de gestação, atualmente o salário-maternidade têm também o cunho de prestação de natureza familiar visando conceder a família o direito de integração e socialização com a criança nos primeiros momentos de sua vida.

Nessa direção, Antônio Borges de Figueiredo e Marcela Gallo de Oliveira:

A concessão do salário maternidade para a mãe biológica não impede a concessão de igual benefício em caso de adoção ou guarda para fins de adoção de criança com idade não superior a oito anos (art. 93- $\mathrm{A}, \S 1^{\circ}$, do Decreto 3.048/99). Idêntico tratamento jurídico pode ser aplicado, em caso de maternidade por substituição, vulgarmente conhecida como barriga de aluguel, a favor das duas seguradas, por interpretação extensiva, lógica ou finalista, senão por analogia (Borges de Figueiredo e Gallo de Oliveira, 2007: 114).

Ainda, Tiago Faggionni Bachur e Tânia Faggionni Bachur da Costa Manso anuem ao relatar que a mãe hospedeira e a mãe genética devem receber o salário-maternidade e a licença à maternidade de 120 dias, ainda que a legislação previdenciária e 
a trabalhista sejam omissas quanto à maternidade substitutiva (Faggionni Bachur e Costa Manso, 2011: 167).

Em sentido contrário, Sergio Pinto Martins, em casos legais de barriga de aluguel no Brasil, discorda que a mãe biológica e a mãe que cedeu seu útero, como por exemplo, a avó que cede o útero para gestar seu neto, possam ambas receber o salário-maternidade, tendo em vista que não há previsão legal para que sejam concedidos dois benefícios com um único fato gerador pela ofensa a regra da contrapartida (Martins, 2017: 539).

Cumpre ressaltar, que o autor ainda permanece com a visão de que o pagamento do salário-materidade seria para que a mãe se recupere dos efeitos do parto. Contudo, nossa jurisprudência tem se adequado aos novos conceitos do Direito de Família e utilizado a analogia à licença maternidade para conceder o benefício para que a mãe hospedeira possa zelar pela criança.

Assim foi julgamento do Conselho Superior da Justiça do Trabalho na decisão do Tribunal Regional do Trabalho da 15ª Região, CSJT - 150/2008-895-15-00-o:

Tem-se como essencial uma interpretação sistemática do artigo 210 da Lei n. ${ }^{\circ}$ 8.112/90 com o artigo $5^{\circ}$, caput, da Constituição da República, que consagra o princípio da isonomia. Com efeito, se o Estatuto da Criança e do Adolescente (artigo 42 da Lei n. ${ }^{\circ} .069 / 90$ ) confere a qualquer pessoa com idade superior a 21 (vinte e um) anos, independente do sexo, o direito à adoção, afigura-se-me normal que um servidor, ainda que não casado, opte por adotar ou obter a guarda judicial de uma criança. Aliás, conduta desta natureza, além de se encontrar em perfeita harmonia com o artigo 227 da Constituição da República, que prevê ser dever do Estado, da família e da sociedade assegurar, com absoluta prioridade, proteção à criança e a adolescente, é digna de louvor, principalmente se levarmos em consideração que vivemos num país que, embora em desenvolvimento, convive ainda com elevado número de crianças em total abandono e às margens da criminalidade. Não é menos verdade que o lapso temporal de 90 dias previsto no artigo 210 da Lei 8.112/90, para gozo de licença de servidora, deve-se ao fato de, em se tratando de criança com idade inferior a 1 (um) ano, serem imprescindíveis, tanto cuidados especiais e essenciais à adaptação ao novo ambiente familiar, como a aquisição de materiais a serem utilizados pela criança e, quiçá, a contratação de uma babá de confiança para zelar pelo menor. Esses cuidados, como se sabe, não deixa de ser primordiais à boa adaptação da criança, apenas por ser o adotante um servidor do sexo masculino que não tenha firmado sociedade conjugal. Aliás, eventual conclusão no sentido de se obstaculizar o direito do servidor implicaria, a meu ver, manifesta ofensa ao princípio constitucional da isonomia, além da consagração de tese que, certamente, não conseguiu acompanhar a evolução da nossa sociedade. ${ }^{8}$

8. Conselho Superior da Justiça do Trabalho. Processo n. CSJT-150/2008-895-15-00.o. 
$\mathrm{O}$ art. 71-A, incluído pela Lei 12.873, de 2013, preceitua que, ressalvado o caso de pagamento do salário-maternidade à mãe biológica e o disposto no art. 71- $\mathrm{B}$, hipótese que o pai pode substituir à mãe na licença, não poderá ser concedido o benefício a mais de um segurado, decorrente do mesmo processo de adoção ou guarda, ainda que os cônjuges ou companheiros estejam submetidos a Regime Próprio de Previdência Social.

Utilizando a analogia para o mencionado caso concreto, resta-se aqui fundamentado o caso de barriga de aluguel quando a mãe biológica que cedeu o óvulo busca a maternidade de substituição, cujo vínculo não é a ascendente em primeiro grau com a criança. Nessa hipótese, pelo fato de a mãe biológica ser uma exceção quanto à cumulatividade do salário-maternidade não há que se falar em ofensa a regra da contrapartida quando a mãe hospedeira (analisa-se analogicamente à mãe adotante) ter direito a referida prestação.

Nesse diapasão, verificamos que há na jurisprudência pátria, notadamente no Tribunal Regional Federal da $5^{a}$ Região, decisão que concedeu 180 dias de licença maternidade à parte autora que tinha se submetido à fertilização in vitro e gestação em «barriga de aluguel», sob a fundamentação de que se tratava de filiação biológica, o que se diferencia da situação de filiação por adoção. Vejamos a ementa:

Constitucional. Administrativo. Licença Maternidade. Prazo de 18o Dias. Fertilização 'In Vitro' em 'Barriga de Aluguel'. Danos Morais. Inexistência. 1. Hipótese em que a autora tendo realizado fertilização 'in vitro' e gestação em 'barriga de aluguel', em virtude das dificuldades em engravidar, pretende seja reconhecido o seu direto à licença maternidade pelo período de 180 (cento e oitenta dias) dias e não de 150 (cento e cinquenta) dias como deferido pela UFPE, bem como indenização por danos morais. 2. Devem ser computados aos prazos previstos nos artigos 207 e 210, da Constituição Federal, os prazos estabelecidos nos Decretos 6.69o/2008 e 6.691/2008, resultando o benefício de 180 (cento e oitenta) dias para a mãe gestante e 150 (cento e cinquenta) dias para a mãe adotante. 3. A autora é, efetivamente, mãe biológica, não importa se a fertilização foi 'in vitro' ou com 'barriga de aluguel'. Os filhos são sanguíneos e não adotivos. A autora faz jus à licença maternidade pelo período de 180 (cento e oitenta) dias, o que se justifica, sobretudo, por serem 03 (três) os filhos. ${ }^{9}$

Nesse propósito, argumenta-se também que nosso texto Constitucional de 1988 possui preceitos hermenêuticos constitucionais que guiam a interpretação sistemática e ampliativa no que rege à concessão do salário-maternidade para a mãe hospedeira e para a mãe genética na barriga de aluguel.

Luis Roberto Barroso ilustra que a interpretação constitucional deve englobar um todo harmônico momento em que nenhum dispositivo deve ser isoladamente levado em consideração (Barroso, 1996: 118).

9. Tribunal Regional Federal da 5 Região. Apelação Cível n. ooo4161- 23.2011.4.05.8300. 
Já quanto a interpretação sistemática, Christiane Oliveira Peter orienta que através desse tipo de interpretação haverá um contexto normativo geral e particular que estabelecem as conexões internas que enlaçam as instituições e as normas jurídicas (Silva, 2005: 274).

Deveras, a interpretação isolada de uma norma dentro de um Estado Constitucional de Direito, lastreado nos direitos fundamentais com eficácia direta e que, por representar posições subjetivas das pessoas como tais, assentes na Constituição - formal e material (Miranda, 1998: 7), dizendo respeito ao ser como pessoa humana e que por isso «são direitos anteriores e superiores ao Estado, isto é, direitos que o homem opõe ao Estado, limitando o poder de governo» (Maluf, 1986: 363), exige uma participação proativa do Judiciário na resolução de conflitos de acordo com as necessidades do caso concreto.

Nessa trilha, o Judiciário deve, num determinado processo e diante da necessidade de se solucionar um caso concreto, suprir uma lacuna ou falha legislativa deixada pelo Poder respectivo, principalmente em questões envolvendo direitos fundamentais, como é o direito à licença maternidade. É «uma atitude, a escolha de modo específico e proativo de interpretar a Constituição, expandindo seu sentido e alcance» (Barroso, 2012: 25).

Assim, se uma norma infraconstitucional admite, pela sua amplitude semântica ou peculiaridades em específico, mais de um sentido interpretativo, deve-se priorizar aquele mais coerente com a Carta Magna e com as garantias nela insculpidas.

Em outras palavras, a interpretação constitucional realizada de forma sistemática, como técnica de interpretação, «impõe a juízes e tribunais que interpretem a legislação ordinária de modo a realizar, da maneira mais adequada, os valores e fins constitucionais» (Barroso, 2009: 301). E tanto deve ocorrer na concessão do salário-maternidade e licença maternidade nos casos de maternidade em substituição, tanto na barriga solidária, quanto na barriga de aluguel.

Aliás, é de se destacar que, na hipótese de ocorrer a barriga solidária, quando a mulher por problemas de infertilidade, busca material doado pelo banco genético e implanta este óvulo com o esperma de seu marido em uma mãe portadora, a concessão do salário e da licença-maternidade ficou bastante simplificada pelo Provimento n. 52 de 14 de março de 2016 do Conselho Nacional de Justiça.

Essa normativa relata que nos casos de gestação por substituição, não mais constará do registro o nome da gestante informado na Declaração de Nascido Vivo. Por esta razão, o conhecimento da ascendência biológica não importará no reconhecimento de vínculo de parentesco entre o doador ou doadora e a pessoa gerada por meio de reprodução assistida. Nesse caso, haverá o registro no nome do casal heterossexuais ou de homoafetivos que poderão gozar do salário e da licença-maternidade na forma da lei através da comprovação da certidão de nascimento da criança. 
Lembramos que em se tratando de um casal homoafetivo feminino só uma das mães poderá gozar do salário e da licença-materidade. Este tema, como visto, anteriormente está em repercussão geral no Supremo Tribunal Federal.

\section{Considerações finais}

O direito de família tem evoluído sobremaneira nos últimos anos. E toda essa evolução, por vezes, não é acompanhada pela legislação.

De fato, novos conceitos de família e filiação que foram introduzidos na sociedade, além da própria evolução da ciência em aspectos com influência direta no direito, como é o caso da reprodução assistida, principalmente na fertilização in vitro. A antiga máxima mater semper certa est já não atende mais a realidade social que se vive hoje.

Nesse campo, envolvendo a filiação, a maternidade e a reprodução assistida, temos a situação da maternidade de substituição, na qual outra mulher atende todo o período de gestação de uma criança fruto do planejamento de outra pessoa ou casal.

Seja pela modalidade barriga solidária, seja pela barriga de aluguel, a questão é que a maternidade de substituição ou cessão temporária de útero é uma realidade na sociedade no mundo e também no Brasil.

Trata-se de assunto que atiça as mais variadas discussões, não apenas no direito de família, mas no campo da bioética e do biodireito, além da própria medicina especializada na reprodução assistida.

Tais discussões alcançam também o direito previdenciário, no tocante à concessão do salário-maternidade e da licença maternidade, para aquela que está gestante e que realizará o parto, e para aquela que será a mãe, em decorrência do planejamento que perfez.

Para se analisar a situação como todo, é preciso rememorar a real finalidade social do salário-maternidade e da licença maternidade, notadamente quando tais institutos de caráter estritamente protetivos estão inseridos num contexto de direitos fundamentais, ligados à maternidade, dentro de um Estado Constitucional de Direito, como é o Brasil, notadamente após a Constituição de 1988, monumento das garantias.

Como vimos, o salário-maternidade e a licença maternidade não têm por objetivo propiciar a mera recuperação da mãe dos efeitos do parto, visão essa antiga e que está ultrapassada no campo do direito previdenciário, principalmente quando se tem em mente os direitos fundamentais ligados à proteção da maternidade e do bom desenvolvimento familiar da criança, dentro do seu melhor interesse.

Nessa linha, a natureza jurídica do salário-maternidade não é apenas proteger as mulheres que dão à luz dos efeitos do parto. É tornar viável a integração dos pais desta criança no ambiente familiar.

É evidente a falta legislativa no campo previdenciário para regular a questão. Por- 
tanto, cabe aos tribunais, diante dessa omissão, resolver a questão, dentro de uma interpretação constitucional e sistemática da legislação previdenciária.

Nessa ordem de ideias e diante dessa forma de interpretar, sempre tendo como norte os direitos fundamentais, chegamos à conclusão de que deve haver a concessão do salário-maternidade e licença maternidade tanto para a mãe hospedeira, quanto para a mãe que planejou aquela gestação na barriga de aluguel.

\section{Referencias}

BACHur, Tiago Faggionni y Tânia Faggioni Bachur da Costa Manso (2011). Licençamaternidade e salário maternidade na teoria e na prática. Franca: Lemos e Cruz.

BARbAs, Stela Marcos de Almeida Neves (2006). Direito ao patrimônio genético. Lisboa: Almedina.

BArros, Sérgio Resende (2003). "Direitos humanos da família: dos fundamentais aos operacionais”. En Câmara Groeninga, Giselle y Rodrigo Cunha Pereira (coordinadores), Direito de família e pscicanálise. São Paulo: Imago.

Barroso, Luis Roberto (1996). Interpretação e Aplicação da Constituição. São Paulo: Saraiva.

-. (2009). Curso de Direito Constitucional Contemporâneo. São Paulo: Saraiva.

-. (2012). "Judicialização, ativismo judicial e legitimidade democrática». Revista [Syn]Thesis, 5 (1): 23-32.

CARdone, Marly (1977/1978). «Igualdade de sexos no trabalho: exemplo da legislação sem eficácia». Arquivos do Instituto de Direito Social (IDS), 17.

DiAs, Maria Berenice (2009). Manual de Direito das Famílias. $5^{\mathrm{a}}$ ed. São Paulo: Revista dos Tribunais.

Diniz, Maria Helena (2006). O estado atual do biodireito. $3^{\text {a }}$ ed. São Paulo: Saraiva.

-. (2009). As lacunas no direito. $9^{\text {a }}$ ed. São Paulo: Saraiva.

Figueiredo, Antônio e Marcela Gallo de Oliveira Borges de (2007). Salário maternidade no RGPS. São Paulo: LTr.

Freire Júnior, Aluer Baptista e Lorraine Andrade Batista (2017). "A cessão temporária de útero: possibilidade legal». Revista Educação, Meio Ambiente e Saúde, Manhuaçu, 7 (4). Disponível em https://bit.ly/3c9A7qI.

FujıTA, Jorge Shiguemitsu (2009). Filiação. São Paulo: Atlas

Gama, Guilherme Calmon Nogueira da (2003). O biodireito e as relações parentais.

Rio de Janeiro: Renovar.

Horvath Júnior, Miguel (2004). Salário-maternidade. São Paulo: Quartier Latin.

Madaleno, Rolf (2011). Curso de Direito de Família. 4a ed. Rio de Janeiro: Gen/ Forense.

Maluf, Said (1986). Direito Constitucional. 19ª ed. São Paulo: Literarias.

Martins, Sergio Pinto (2017). Direito do trabalho. $33^{\text {a }}$ ed. São Paulo: Saraiva. 
Miranda, Jorge (1998). Manual de Direito Constitucional. Tom. IV. Coimbra: Coimbra.

OIT, Organização Internacional do Trabalho (1952). Dispõe sobre normas mínimas da seguridade social Convenção n. 102/1952. Disponível em https://bit.ly/2X8Sg3v.

Oliveira, José Sebastião de (2002). Fundamentos constitucionais do direito de família. São Paulo: RT.

Pastor, José M. Almansa (1991). Derecho de la seguridad social. Madrid: Tecnos.

Presotto, Andréa Regina Galvão (2011). «Internacionalização dos sistemas de seguridade social-perspectiva Brasil». Dissertação de mestrado em direito, Universidade de São Paulo.

Silva, Christiane Oliveira Peter (2005). Hermenêutica de Direitos Fundamentais. Brasília: Brasília Jurídica.

Silva, Edineia Rosélia Nascimento (2016). «Barriga solidária: Limites jurídicos e o direito fundamental ao próprio corpo». Dissertação. Mestrado, Universidade Católica de Pernambuco, Recife.

Silva, Ivan de Oliveira (2008). Biodireito, bioética e patrimônio genético brasileiro. São Paulo: Pillares.

Szaniawski, Elimar (2019). Diálogos com o direito de filiação brasileiro. Belo Horizonte: Fórum

Teixeira, Carolina Rocha Pereira (2016). «A maternidade de substituição e o conflito de presunção de maternidade certa: estudo de casos». Revista Jurídica do Tribunal de Justiça do Distrito Federal e Territórios, 108 (1): 125-144. Disponível em https://bit.ly/zerW 8lT.

Venturi, Augusto (1995). Los fundamentos científicos de la seguridad social. Madrid: Ministerio de Trabajo y Seguridad Social, 1995.

\section{Sobre os autores}

Gilberto Ferreira Marchetti Filho é Mestre em Processo Civil e Cidadania pela Universidade Paranaense. Assessor Jurídico do Tribunal de Justiça do Mato Grosso do Sul. Professor de Direito Civil e Processo Civil na graduação e pós-graduação no Centro Universitário da Grande Dourados. O seu endereço de correio electrónico é gilberto.marchetti@unigran.br.

Juliana de Oliveira Xavier Ribeiro é Doutoranda em Direito pela Pontifícia Universidade Católica de São Paulo, e pela Universidade Autônoma de Lisboa. Mestre em Direito pela Pontifícia Universidade Católica de São Paulo. Professora e coordenadora de cursos de pós-graduação em Direito. Autora de obras jurídicas. O seu endereço de correio electrónico é juliana_x_ribeiro@yahoo.com.br. 